\title{
Correction: Dynamic behavior of rearranging carbocations - implications for terpene biosynthesis
}

\author{
Stephanie R. Hare and Dean J. Tantillo*
}

\section{Correction}

Address:

Department of Chemistry, University of California-Davis, 1 Shields Avenue, Davis, CA 95616, USA

\section{Email:}

Dean J. Tantillo* - djtantillo@ucdavis.edu

* Corresponding author

Keywords:

carbocation; density functional theory; dynamics; mechanism; terpene
Beilstein J. Org. Chem. 2017, 13, 1669.

doi:10.3762/bjoc. 13.161

Received: 27 July 2017

Accepted: 02 August 2017

Published: 15 August 2017

Guest Editor: J. S. Dickschat

(c) 2017 Hare and Tantillo; licensee Beilstein-Institut. License and terms: see end of document.

This correction refers to Beilstein J. Org. Chem. 2016, 12, 377-390. doi:10.3762/bjoc.12.41

The originally published Figure 6 had several mis-drawn structures with charges in incorrect locations. These errors have been corrected in the new version (see Figure 1).

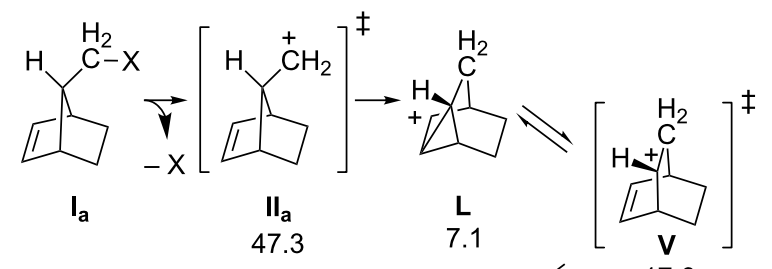

$$
\begin{aligned}
& \underset{\mathrm{I}_{\mathbf{s}}}{\mathrm{C}_{\mathrm{C}}^{\mathrm{H}_{2}}}
\end{aligned}
$$

Figure 1: Corrected Figure 6 of the original article. The portion of the norborn-2-en-7-ylmethyl cation PES examined by Ghigo et al. [60]. Energies reported are electronic energies, including zero-point corrections (ZPE), at the B3LYP/6-31G(d) level of theory and are all relative to that of $\mathbf{G}$ [61-63] (for references see original article).

\section{License and Terms}

This is an Open Access article under the terms of the Creative Commons Attribution License (http://creativecommons.org/licenses/by/4.0), which permits unrestricted use, distribution, and reproduction in any medium, provided the original work is properly cited.

The license is subject to the Beilstein Journal of Organic Chemistry terms and conditions:

(http://www.beilstein-journals.org/bjoc)

The definitive version of this article is the electronic one which can be found at: doi:10.3762/bjoc. 13.161 